\title{
Los debates sobre la regulación de la prestación personal en Filipinas durante el siglo XIX ${ }^{1}$
}

\author{
Luis Ángel Sánchez Gómez.
}

Universidad Complutense de Madrid

El trabajo obligatorio de la población indígena, la prestación personal, jugó un destacado papel durante los más de tres siglos de presencia española en Filipinas, erigiéndose casi en el único mecanismo disponible para la construcción y mantenimiento de la deficiente estructura de comunicaciones de las islas, además de para el sostenimiento de otros servicios públicos. En el presente artículo estudiamos los ensayos de regulación de esta forma de exacción tributaria articulados durante el siglo XIX, encaminados, al menos en teoría, a la eliminación, o al menos la reducción, de los innumerables abusos que caracterizan su administración a lo largo de toda la centuria, al igual que había ocurrido en las etapas anteriores.

La prestación personal, conocida en Filipinas como "polos y servicios", es una forma de exacción tributaria mediante la cual la población indígena ha de trabajar de forma gratuita y obligatoria para la administración colonial durante un cierto número de días al año. Como señala Phelan, ${ }^{2}$ este peculiar sistema de tributación laboral se documenta desde los primeros momentos de la presencia española en Filipinas, viéndose facilitada su instauración por la existencia de una forma similar de trabajo obligatorio en la etapa prehispánica. Es indudable que durante los siglos XVI y XVII esta prestación estuvo directamente relacionada con el desarrollo del sistema de encomiendas. En este contexto, encomenderos y otros personajes de la clase colonizadora buscaron una mayor y más exhaustiva explotación del trabajo indígena para aumentar la producción y los beneficios, lo cual, unido a la necesidad de pagar el tributo —en metálico o en especie - por parte de la población filipina, produjo notables desequilibrios socioeconómicos en las islas. Pese a todo, es notorio que ni las encomiendas ni la misma prestación personal obligatoria tuvieron en Filipinas,

1 El artículo que presentamos recoge en parte información inédita - revisada, corregida y actualizada - perteneciente a la tesis doctoral del autor, titulada Las principalías indígenas y la administración española en Filipinas, leída en 1989 y reprografiada por la Universidad Complutense en 1991.

2 Phelan, J. L.: The Hispanization of the Philippines. Spanish Aims and Filipino Responses (1565-1700). Madison, University of Wisconsin Press, 1967, pág. 99. 
en ningún momento, una importancia equiparable, ni cuantitativa ni cualitativamente, a la que se documenta en el continente americano. ${ }^{3}$

Aunque la guerra contra los holandeses, iniciada a finales de 1609, produjo un incremento y endurecimiento temporal de la prestación en algunas provincias, debido básicamente al corte y transporte de maderas para la construcción de navíos de guerra, la regulación, muy básica, de este servicio había quedado establecida justo desde unos meses antes en aquel mismo año. En efecto, una real cédula de 26 de mayo de 1609 (libro VI, título 12, ley 40 de la Recopilación de Leyes de Indias) prohibía que se repartieran indios para trabajos particulares o públicos, pues debían ser contratados chinos o japoneses que se encontraran en Manila, o indios que acudieran de forma voluntaria, todos debidamente remunerados. Esos repartimientos sólo podrían hacerse "para cosas forzosas e inexcusables, pues en materia tan odiosa no ha de bastar el mayor beneficio de nuestra real hacienda o más comodidad de la república, y todo lo que no fuere preciso para su conservación [de las islas] pesa menos que la libertad de los indios". El paternalismo de la ley es bien evidente y aún se hace sentir más cuando advierte de que se señalen las horas de trabajo diarias del indio "atendiendo a las pocas fuerzas y débil complexión de su naturaleza”. Continúa la real cédula ordenando que no se traslade a los naturales a grandes distancias, que se les ocupe de tal forma que puedan hacer compatible la prestación personal con el trabajo en sus tierras y que se castigue con severidad los abusos que pudieran cometer sus caciques indios o las autoridades civiles y religiosas españolas en la organización y desarrollo de los trabajos. ${ }^{4}$

3 Sobre la encomienda filipina durante las primeras décadas de la presencia española en las islas, puede consultarse la obra de Hidalgo, P.: Encomienda, tributo y trabajo en Filipinas (1570-1608), Madrid, Universidad Autónoma de Madrid, Polifemo, 1995.

4 Aunque su carácter es diferente, una forma más de trabajo personal obligatorio es la "tanoría". Los indios e indias tanores (o tánores) se repartían semanalmente entre religiosos y alcaldes mayores para servirles gratuitamente en tareas de cocina, limpieza, compras, etc. Estos mismos indios, y en otros casos todo el pueblo, debían igualmente abastecer de pescado a los religiosos durante las vigilias y cuaresmas. Ambas prácticas fueron prohibidas, obligándose a pagar un sueldo en caso de ser requeridos tales servicios, de acuerdo con sendas reales cédulas de 1608 y otra más de 1610 , recogidas en la ley 41, título 12, del libro VI (las dos primeras) y la ley 43 del mismo título y libro, la última. Estas prohibiciones serán renovadas en las ordenanzas de buen gobierno, lo que delata la supervivencia de las tanorías. De hecho, este servicio, mejor dicho, el pago por su redención, subsistió en la provincia de Albay hasta 1882. Fue suprimido a solicitud de su alcalde mayor, Juan Álvarez Guerra, quién informó al gobernador general Fernando Primo de Rivera, en mayo de 1880, de que su provincia era la única de Filipinas donde todavía se pagaba la reserva de tanorías y guardias, hecho que consideraba injusto, aunque fuera rentable para las arcas provinciales. Una real orden de 8 de julio de 1880 suprimió la obligación de aquel pago, pero diversos problemas impidieron su aplicación hasta abril de 1882 . Archivo Histórico Nacional, Ultramar, 5.243, tercera parte, exp. 47. 
Además de en las Leyes de Indias, el sensible mundo de los trabajos obligatorios aparece reflejado igualmente en las ordenanzas de buen gobierno, dictadas por varios gobernadores generales de Filipinas durante los siglos XVII y XVIII. Las de Fausto Cruzat y Góngora, de 1696, además de insistir en la prohibición de la existencia de indios tanores (cap. 21), advierten a los alcaldes mayores, en el capítulo 19, de que no permitan que estén reservados de polos y servicios otras personas que no sean los ancianos y los jóvenes, los cabezas de barangay ${ }^{5}$ y sus primogénitos, y los cantores, sacristanes, porteros y cocineros al servicio de iglesias y casas parroquiales. ${ }^{6}$ Los restantes varones deberán cumplir con la prestación personal "aunque hayan sido gobernadores capitanes y obtenido otros oficios de guerra, con sueldo o sin él, o por otro cualquier título, causa o razón, ni por ser honrados principales ni por conciertos que hagan unos con otros por razón de sus antiguiedades $^{7}[\ldots]$ ".. El mismo capítulo hace referencia a la necesidad de controlar las reservas de esos polos y servicios, pues su mala o corrupta gestión incide en que hayan de trabajar y sufrir más "los hombres más flacos, que son los timauas". ${ }^{8}$ Muy similares indicaciones se habían hecho en ordenanzas previas y se harán en las posteriores - como ocurre con las de José Raón, de 1768, aunque éstas sean bastante más severas, en todos los órdenes, con las autoridades españolas-, siempre con escasos o nulos resultados sobre el control efectivo de la prestación personal.

La organización irregular de los trabajos y, sobre todo, el cobro fraudulento de redenciones y fallas ${ }^{9}$ por parte de las autoridades locales indígenas - $\mathrm{o}$ su defraudación por las autoridades provinciales españolasserán reiteradamente denunciados. Así se hace, por ejemplo, en otro tipo de ordenamientos, como ocurre en las "Ordenanzas municipales para el buen

5 Tras la conquista española de Filipinas, el antiguo dato o datu, esto es, el personaje principal de las comunidades indígenas, pasó a denominarse oficialmente cabeza de barangay, conservando - además de ciertos privilegios económicos - el control sobre un sector de los nuevos pueblos. No obstante, su función básica será siempre la recaudación del tributo entre los miembros de su "cabecería".

6 Sin embargo, el capítulo 39 de las mismas ordenanzas, según auto acordado por el mismo Cruzat el 14 de mayo de 1697, reforma el citado capítulo 19 y retira la reserva del tributo y los servicios personales a los cocineros de los párrocos.

7 "Ordenanzas de Gobierno de Don Fausto Cruzat y Góngora", en Papeles sobre las misiones en Filipinas. Siglos XVII-XVIII, Biblioteca Nacional, ms. 11.014, ff. 297v-258.

8 Esto es, la clase baja.

9 Abona el valor de la redención quien desea verse libre de la prestación personal. La falla es la cantidad pagada, a posteriori, por cada día que no se acude a ese mismo servicio. Estos últimos pagos no correspondían a ningún tipo de redención previa al trabajo, lo que facilitaba aún más la comisión de fraudes por parte de las autoridades indígenas y provinciales. 
régimen y gobierno de la provincia de Ilocos", dictadas en 1743 por José Ignacio Arzadun y Rebolledo, oidor y alcalde del crimen de la Audiencia de Manila. ${ }^{10}$ En el capítulo 11 se advierte de que "los gobernadorcillos ${ }^{11}$ de los pueblos de dicha provincia, excediéndose de sus facultades y jurisdicción, han reservado de polos y servicios personales a muchos indios por diferentes cantidades de dinero [...]". Al parecer, los gobernadorcillos justifican tales actuaciones afirmando que con los ingresos obtenidos se pagan los derechos de elecciones, títulos de los ministros de justicia y otros gastos de la administración local. Reconoce el juez que esto es cierto en algunos casos (dada la penuria económica existente), pero asegura que en otras muchas ocasiones las autoridades indígenas se quedan con buena parte de lo recaudado.

Y por ofrecer un ejemplo más del siglo XVIII, haremos referencia a la conocida "Relación del Estado de las Islas Visayas, y de todas las Filipinas, de los males que padecen y de los medios que para su restauración propone a la Real Católica Majestad por medio de su Secretario [...]", escrita por Pedro Vértiz, fechada a 31 de diciembre de $1778 .{ }^{12}$ En dicho informe, y al margen de la denuncia de otros fraudes, se destaca que los cabezas de barangay utilizan a los polistas para su servicio particular, prohibiéndoles ausentarse sin su permiso e imponiéndoles todo tipo de

10 Reproducidas en la "Copia de las diligencias remitidas por el Licenciado D. Félix de Sousa, Juez Pesquisidor nombrado contra D. Pedro Nevado, Alcalde mayor de la Provincia de Ilocos", segunda pieza, ff. 104v-116. AHN, Consejos, 21.020.

11 "Gobernadorcillo" es el término que designa en Filipinas, durante la etapa española, a los alcaldes de los municipios indígenas. En realidad, sus funciones y prerrogativas están muy alejadas de las que poseen los alcaldes peninsulares y tampoco las poblaciones indígenas son auténticos municipios. Sobre la organización político-administrativa de las poblaciones indígenas filipinas y sus complejas y difíciles relaciones con la administración colonial española, pueden consultarse algunos de nuestros trabajos, entre ellos Sánchez Gómez, L. A.: "Élites indígenas y política colonial en Filipinas (1847-1898)", en C. Naranjo, M. A. Puig-Samper y L. M. García Mora (eds.), La Nación soñada: Cuba, Puerto Rico y Filipinas ante el 98. Actas del Congreso Internacional celebrado en Aranjuez del 24 al 28 de abril de 1995, Aranjuez, Doce Calles, págs. 417-427.

12 Pedro Vértiz fue uno de los cuatro intendentes de provincia (para Ilocos, Camarines, Iloilo y Cebú, respectivamente) nombrados por real orden de 1 de octubre de 1780 . Vértiz fue el único que tomó posesión de su cargo. Llegó a Manila en diciembre de 1787 y su destino era la intendencia de Cebú. Diversas circunstancias hicieron que no arribara a la ciudad de Cebú hasta el 10 de junio de 1788. Apenas tuvo tiempo de realizar labor alguna, ya que el 29 de julio de ese mismo año recibió un oficio del capitán general comunicándole la supresión de las intendencias provinciales. Sobre las intendencias en Filipinas durante el siglo XVIII y el informe de Vértiz, ver García de los Arcos, M. F.: La intendencia en Filipinas, Granada, Universidad de Granada, pág. 109-114. También es de gran interés el más reciente estudio de Fradera, J. M.: Filipinas, la colonia más peculiar. La hacienda pública en la definición de la política colonial, 1762-1868, Madrid, CSIC, 1999, págs. 71-131. El informe de Vértiz se conserva en el Archivo General de Indias, Ultramar, 613. 
multas y penas corporales. En realidad, esta práctica se encuentra extendida por todo el archipiélago: los indios principales no pueden disponer legalmente de siervos o esclavos (que lo eran básicamente por deudas durante la etapa prehispánica y aún después) y recurren, para el cultivo de sus tierras y el servicio doméstico, a esa mano de obra ilegal y gratuita que obtienen de los polistas.

Ya durante el siglo XIX, el tema de la prestación personal se erige en una de las principales cuestiones de debate y polémica en el contexto de las propuestas sobre las reformas de la administración de Filipinas. La razón principal para que esto ocurra no debemos buscarla tanto en lo opresivo del sistema de trabajo obligatorio establecido, como en la continuidad de los abusos a que da lugar su gestión, ${ }^{13}$ al tiempo que reiteradamente se llama la atención sobre la escasa rentabilidad pública que se obtiene del mismo. En la práctica, la utilidad legal de la prestación personal se materializa en lo que en diferentes reglamentos se denominan servicios ordinarios y extraordinarios. Entraban en la primera categoría los servicios prestados por los indígenas en los tribunales ${ }^{14}$ de los pueblos auxiliando a las autoridades locales; las guardias en garitas y baluartes; la custodia y conducción de presos y el servicio de "cuadrilleros" 15 — siempre que no bastara con la participación de la escasa fuerza armada disponible—; la conducción de pliegos y el mantenimiento general de las obras y servicios existentes. Por su parte, los servicios extraordinarios afectaban a la construcción y reparación de vías de comunicación, puentes y edificios oficiales, tanto civiles como religiosos; los cortes y traslados de maderas e incluso la roturación y cultivo de terrenos incultos, siempre que su explotación fuera en beneficio de los "caudales de propios". Por supuesto, eran moneda común los problemas

13 Ofrecemos información detallada sobre los fraudes cometidos por autoridades provinciales y élites indígenas en Sánchez Gómez, L. A.: "Las contradicciones del colonialismo: conflictos en la administración provincial de Filipinas durante el siglo XIX", Cuadernos de Historia, Instituto Cervantes, Manila, 2-3, 1998, págs. 87-102 y en "Corrupción y justicia colonial: procesos contra jefes de provincia en Filipinas durante el siglo XIX”, en M. Luque, J. J. Pacheco y F. Palanco (coords.), 1898: España y el Pacífico, Madrid, Asociación Española de Estudios del Pacífico, 1999, págs. 133145. Recordemos, por otra parte, que al margen de los fraudes propiamente dichos, los habitantes de determinadas provincias padecen un servicio de prestación personal ciertamente opresivo. Los residentes en la provincia de Tondo, cuya capital es la ciudad de Manila, son indudablemente quienes salen peor parados, debido a la enorme cantidad de tareas y trabajos que exige la administración de la capital del archipiélago. Puede consultarse al respecto la real cédula fechada a 18 de octubre de 1743, que reproduce Rodríguez Bérriz, M.: Diccionario de la Administración de Filipinas. Manila, Imp. de “Amigos del País", 2. a serie, 7 vols., 1888-1895, vol. 2, págs. 261-263.

14 Las casas de gobierno locales.

15 Especie de guardia local. 
surgidos en relación con el suministro de materiales y herramientas, al tiempo que se carecía casi por completo de personal cualificado para la dirección de las obras y tampoco estaban preparados todos los polistas para desarrollar las tareas exigidas en el ámbito de los servicios extraordinarios.

En las páginas que siguen, mostraremos los procesos de reforma y "contrarreforma" desarrollados en las islas y en la península para reglamentar la prestación personal en Filipinas durante el siglo XIX, y esto es algo que obliga a la revisión de un sinnúmero de informes y proyectos que en su inmensa mayoría acaban en vía muerta. Este repaso saca a la luz buena parte del extremadamente burocrático proceso de estudio e información que tiene lugar en la península durante toda la centuria, y especialmente en su segunda mitad, para reformar la administración del archipiélago. El sistema, como podremos comprobar, adquiere tonos casi esperpénticos, con interminables trasiegos de papeles, espaciados por intervalos más o menos largos de olvidos, bloqueos o pérdidas de documentación, que alargan los procesos de forma inimaginable. Obviamente, todo esto se produce no sólo por la lentitud y complejidad del aparato burocrático, sino por la obsesión existente en la península, aún en los momentos de mayor efervescencia liberal, por ralentizar al máximo — cuando no paralizar - los cambios, meramente administrativos casi todos ellos, que pudieran introducirse en el archipiélago. ${ }^{16}$

Como hemos comprobado, la prestación personal había funcionado en Filipinas sin que existiera una reglamentación específica al respecto, ya que las indicaciones hechas en las Leyes de Indias y en las ordenanzas de buen gobierno resultaban demasiado vagas. Pese a todo, tanto desde las más altas instancias de gobierno insulares como peninsulares se afronta con no demasiada convicción y de forma totalmente descoordinada la delicada situación de este anacrónico pero indispensable recurso. Es ilustrativo al respecto que una circular ${ }^{17}$ de la Dirección General de Administración Local de Filipinas, de 20 de septiembre de 1861, tratando de dar respuesta a las reclamaciones de indígenas de varias provincias sobre el reparto y ejecución de la prestación personal, informa de un superior decreto por el

16 Un útil repaso a la política general de España respecto al archipiélago filipino, entre 1812 y 1898, es el que presenta en su libro, de título no muy afortunado, Celdrán Ruano, J.: Instituciones hispanofilipinas del siglo XIX, Madrid, Mapfre, 1994.

17 La reproduce Artigas, M.: El Municipio filipino. Compilación de cuanto se ha prescrito sobre este particular e historia municipal de Filipinas desde los primeros tiempos de la dominación española, Manila, 1894, II, págs. 126-127. 
que se ordena la "más estricta observancia", respecto al problema, de la ley 40, título 12, del libro VI de la Recopilación de Leyes de Indias que ya citáramos líneas atrás y que, como vimos, resulta escasamente concreta en sus apreciaciones. También se remite al capítulo 57 de las ordenanzas de Raón sobre limpieza de ríos y reparación de puentes y caminos. Se echa mano, en definitiva, de un ordenamiento legal con más de dos siglos de antigüedad.

No obstante, y pese a que existe un casi total vacío legal al respecto, durante la primera mitad del XIX se plantea algún ensayo de regulación básica de ciertos aspectos de la prestación. Así, con fecha 30 de octubre de 1827 el gobierno superior de las islas fija su duración en cuarenta días, y en tres pesos la cantidad a abonar por la redención total. ${ }^{18}$ Años después, en 1852, se documenta el primer reglamento específico sobre dicho servicio, redactado por Rafael Cerveró, alcalde mayor de Cebú. El citado ordenamiento, fechado a 30 de marzo de 1852, fue aprobado por el gobierno superior de las islas el 13 de abril de ese mismo año, entrando en vigor al mes siguiente. En los años 60 del siglo pasado era aplicado, con autorización oficial superior, en Cebú y Bohol, y sin haber recibido dicha sanción en la provincia de Antique, en la isla de Panay, documentándose también informes para su posible aplicación en todo el archipiélago de las Visayas. ${ }^{19}$

Pero la administración seguía sin disponer de una legislación eficaz y de aplicación general a todo el archipiélago. Por real orden de 29 de abril

18 El dato lo aporta la Dirección General de Administración Local, en un informe de noviembre de 1869 sobre una reclamación de los vecinos de Taal (Batangas) acerca de la prestación personal. Este informe se incluyó en el amplio expediente que sobre dicho servicio fue remitido a estudio del Consejo de Estado en 1881. AHN, Ultramar, 5.343, segunda parte, exp. 2.

19 Estos informes, fechados entre 1861 y 1864 y redactados por varios gobernadores de provincias del archipiélago de Visayas y por el propio gobierno civil de esta agrupación insular existente en aquella época, se conservan en AHN, Ultramar, leg. 5.343, segunda parte, exp. 4. En el expediente se incluye copia del reglamento redactado por Cerveró. En los informes citados se destaca que tras la aplicación de este reglamento ha mejorado sensiblemente el servicio de la prestación personal, acabando casi por completo con los tradicionales abusos ejercidos por las autoridades indígenas en su gestión. El reglamento de Cerveró, que era bastante prolijo, consideraba las cantidades recaudadas por el pago de las redenciones como un arbitrio municipal y señalaba que el valor de dicha redención habría de ser fijado por el jefe de provincia de acuerdo con el valor mínimo del jornal más bajo en cada población, lo cual, evidentemente habría de dar lugar a abusos por parte de esas autoridades provinciales. Por otra parte, fijaba un sistema bastante riguroso de inspección del servicio, con la intervención de "visitadores" remunerados decorosamente. También consideraba que cada polista habría de dedicarse, en todos sus trabajos, a un mismo tipo de actividad, acorde con sus condiciones y aptitudes. Por supuesto, no dejaba de ordenar cuáles habrían de ser las penas impuestas a los contraventores del servicio, entre las que se incluían los famosos bejucazos, esto es, los golpes infligidos con flexibles varas de bejuco. 
de 1860, se propuso al gobierno de Filipinas que reglamentase de un modo definitivo la prestación, trasladándose el encargo a la recién creada - lo fue en 1858- Dirección General de Administración Local. ${ }^{20}$ Redacta el nuevo reglamento ${ }^{21}$ Agustín Santayana, jefe del centro, tomando como eje central, al margen de otras disposiciones generales, el plan de Cerveró. Según informes del Consejo de Filipinas, ${ }^{22}$ dicho ordenamiento propiciaba notablemente los abusos, ya que disponía - como hacía el propio plan de Cerveró- que fueran los jefes de provincia quienes fijaran anualmente el precio de la redención del servicio, de acuerdo con el coste de los jornales - de valor muy variable - y además requería de una compleja documentación. Pese a todo, el proyecto fue aprobado por el Real Acuerdo, remitiéndose a Madrid en agosto de 1860. En la metrópoli será modificado, sin demasiadas prisas, hasta dar forma al texto del real decreto de 11 de noviembre de 1863 que, con reglamento incluido, se remite a las islas. ${ }^{23}$ Este proyecto incluía una muy importante novedad: declaraba sujetos a la prestación - $\mathrm{O}$ a su redención - a todos los varones domiciliados o con residencia fija en las islas —indios, españoles y extranjeros—, desde los 18 años - dentro de la patria potestad - o desde los 16 - fuera de ella- hasta los $60 .{ }^{24}$ Esta trascendental variación fue considerada improcedente por

20 En este breve repaso histórico, desde 1852 a 1873, seguiremos las líneas marcadas por el Consejo de Filipinas en su dictamen sobre el expediente de la prestación personal — que comentamos en el texto- de marzo de 1876. AHN, Ultramar, 5.315, primera parte, exp. 7.

21 Existe copia en AHN, Ultramar, leg. 5.343, primera parte, exp. 1, docs. 7 y 8.

22 Órgano consultivo creado en diciembre de 1870. Se puede ampliar información en Sánchez Andrés, A.: "Los organismos consultivos del Ministerio de Ultramar y el gobierno de las colonias del Pacífico (1863-1899)", Revista Española del Pacífico, 4, 1994, págs. 65-74.

23 Real decreto y reglamento organizando el servicio de prestaciones personales y la construcción de obras públicas en Filipinas, Madrid, Imprenta Nacional, 1863.

24 No obstante, la nómina de exceptuados (según el artículo segundo) era extensa: ordenados in sacris; militares en servicio activo; empleados y auxiliares en la dirección y administración de la prestación personal cuyo trabajo no sea retribuido; gobernadorcillos y ministros de justicia mientras desempeñen sus cargos y el año que cesen en ellos; cabezas de barangay en ejercicio; quienes hayan ocupado durante diez años el cargo de gobernadorcillo o quince el de cabeza de barangay sin nota negativa; maestros de las escuelas gratuitas y quienes lo hayan sido durante quince años; fieles y estanqueros de la Real Hacienda, mientras ejerzan estos cargos; doce sirvientes del monasterio de Santa Clara y los sacristanes, porteros y cantores de las iglesias catedrales, parroquiales y conventos; vacunadores (más conocidos como "vacunadorcillos"); intérpretes y "testigos acompañados" de los juzgados de primera instancia y de los gobernadorcillos y tenientes de justicia; quienes estuviesen exentos de tributo por enfermedad, pero no los que disfrutan esta exención por privilegio; quienes presten servicios que por disposición del gobierno supremo se declaren equivalentes a la prestación personal. En el mismo real decreto se fijaba en 24 el número de días anuales dedicados a la prestación personal y en dos pesos (o 2,5 según las provincias) la redención total del servicio. El reglamento distinguía entre servicios ordinarios (limpieza y guardia de edificios públicos) y extraordinarios (construcción y reparación de obras públicas) y daba las normas apropiadas para su ejecución. 
el gobierno de Filipinas, por lo que se suspendió la ejecución del decreto, ${ }^{25}$ explicándose las razones al recién creado Ministerio de Ultramar en carta reservada de 8 de febrero de 1864. En la misma, se informaba de que sería remitido a la península otro reglamento elaborado de nuevo por la Dirección General de Administración Local. Desde Madrid, se advierte de la imposibilidad de alterar el reglamento de noviembre de 1863; no obstante, esperan la llegada del proyecto citado. Éste se remite - sin estar totalmente perfilado - en octubre de 1864. Según el Consejo de Filipinas, era un proyecto sencillo, en el que se proponía que la redención se abonara en un papel especial, para evitar abusos, también organizaba un "cuerpo de directores e inspectores de las obras provinciales y municipales".

En cualquier caso, todos estos trabajos no acaban teniendo vigencia legal alguna, ni siquiera el de noviembre del 63. Será en 1869 cuando vuelva a plantearse una nueva alternativa para la reglamentación de la prestación personal, elaborada en este caso por la "Comisión de reformas administrativas de Manila", creada en octubre de aquel año. ${ }^{26}$ El nuevo proyecto propone reducir el servicio a sólo diez días al año - frente a los cuarenta vigentes_-, prohíbe la redención en metálico — se admite únicamente la sustitución hombre por hombre - y obliga a cada polista al pago de un duro anual como compensación al Estado.

25 En varias obras sobre historia de Filipinas se menciona este real decreto, considerando que fue aplicado de forma efectiva en el archipiélago y que sirvió, a partir de entonces, para regular el servicio de la prestación personal. Insistimos en que no fue así, y que el gobierno de las islas suspendió tajantemente su aplicación. El Consejo de Filipinas —en el comentario que venimos siguiendo- reconoce que el deseo del gobierno de Filipinas de excluir a españoles y extranjeros de la prestación personal razón por la que suspende la aplicación del decreto - no se fundamenta en una cuestión de vanidad o privilegio, sino de "conveniencia social". Sin embargo, el asunto se complica por la cuestión de los chinos. Éstos se encuentran obligados a cumplir con la prestación desde el 1 de julio de 1867. Pero resulta que, por el tratado establecido con China en noviembre de 1868, todos los residentes en Filipinas originarios de aquel país tienen los mismos derechos que cualquier otro extranjero. Esto obliga a incluir en la prestación personal a todos los españoles y extranjeros o a excluir igualmente a todos, incluidos los chinos, hecho este último que resultaría muy negativo para los fondos locales y que causaría disgusto entre los indígenas. Por esta razón, opina el Consejo que debería proponerse incluir tanto a españoles como a extranjeros (sin distinción) entre los obligados a cumplir con la prestación personal.

26 En ese mismo año, se crea en Madrid una "Junta especial de reformas" y una "Comisión consultiva de reformas" sobre la administración filipina, todo ello en el nuevo contexto sociopolítico que se abre en España tras el triunfo de la revolución de 1868. Sobre la labor desarrollada por estas comisiones y la de Manila, puede consultarse el "Resumen comparativo de las reformas propuestas por las Juntas y Comisiones informativas de las islas Filipinas", que forma parte de unos Papeles relativos a las provincias de Ultramar, recopilados por E[ugenio] A[lonso] S[anjurjo], doc. n. ${ }^{\circ} 28, \mathrm{ff}^{4} 457-468 \mathrm{v}$. Biblioteca Nacional, ms. 13.228. Algunas cuestiones de la administración colonial en Filipinas durante el Sexenio las aborda Santaló i Peix, J.: "La administración colonial española en Filipinas durante el Sexenio: toma de conciencia de una problemática particular y voluntad reformadora (1869-1879)", Revista Española del Pacífico, 7, 1997, págs. 65-75. 
Habrá que esperar nada menos que hasta 1876 para que el Consejo de Filipinas informe sobre dicho proyecto de reforma, ${ }^{27}$ haciéndolo entonces desde una perspectiva marcadamente crítica. ${ }^{28}$ En primer lugar, consideran que la reducción a diez días significa tanto como acabar con la prestación; además, argumentan que la población no sufre en realidad por la duración del servicio, sino por los abusos que genera su gestión. En cuanto a la sustitución hombre por hombre, creen que no sería practicable en muchas provincias y que en las restantes tendría un muy elevado coste, pues si el valor de la redención alcanza en la actualidad tres duros anuales, subiría hasta seis, ocho o diez en forma de sueldo para los sustitutos. Por último, el nuevo impuesto que se propone por un valor de cinco pesetas anuales se vería como una duplicación del tributo, sin que ello supusiera en contrapartida la redención del trabajo o la eliminación de los abusos. El Consejo propone que se reduzca el servicio a 24 días y que, para evitar abusos, la redención se haga mediante un papel especial de venta en los estancos, para 8, $10 \mathrm{o}$ los 24 días. Quedarían suprimidas las fallas, consideradas como el principal elemento generador de corrupción.

Asentadas tales bases, el Consejo se enfrenta a la espinosa cuestión de quiénes estarían obligados a contribuir con la prestación personal. Consideran que habría de hacerse extensiva no sólo a los indígenas, sino a todos los españoles y extranjeros residentes en las islas, con las limitaciones de edad ya acordadas; estarían exentos todos aquellos que enumeraba el decreto de noviembre de 1863, según el dictamen original, aunque tras las modificaciones introducidas se retira la exención a los ordenados in sacris, a los gobernadorcillos y a los cabezas de barangay que ya no estuvieran en ejercicio, que hasta entonces estaban exentos tras varios años de servicio continuado.

La redacción definitiva del dictamen lleva a los consejeros Manuel Azcárraga y Tomás López Berges a la elaboración de un voto particu-

27 En Sánchez Gómez: "Vísperas del 98...”, págs. 19-21, contextualizamos el marco político del último tercio del siglo XIX en el que se inserta el parón de las reformas encaminadas a mejorar la administración de Filipinas, que afecta a los debates sobre la reglamentación de la prestación personal.

28 El dictamen, elaborado por los consejeros Pablo Ortiga y Rey, Manuel Azcárraga y Gabriel Álvarez, es el núcleo central al que sirven de preliminares los datos históricos incluidos en el texto. Dicho dictamen está fechado a 5 de enero de 1876 y fue aprobado, con modificaciones, el 10 de marzo del mismo año (AHN, Ultramar, 5.315, primera parte, exp. 7, doc. 3). Este informe culmina un trabajo iniciado en abril de 1872, cuando el Consejo - para dictaminar sobre lo propuesto por la Comisión de Manila- solicitó del Ministerio de Ultramar toda la documentación existente sobre la prestación personal. Hasta un año más tarde, el Consejo no recibe lo solicitado. Desde este momento, se inicia en ese centro un proceso de congelación voluntaria de los dictámenes sobre las reformas de Filipinas, que dura hasta el citado año de 1876. El expediente, con todos los antecedentes, se encuentra en AHN, Ultramar, 5.343, segunda parte, exp. 3 . 
lar. ${ }^{29}$ Plantean, en primer lugar, y como era previsible, que la supresión de las "diferencias entre razas" debe abordarse en el futuro y de manera pausada. Esa "igualación radical" hace posible el desarrollo de "peligrosas teorías que pueden afectar al prestigio y seguridad de nuestra dominación". Consideran que debe "elevarse a los de abajo" y no "bajar a los de arriba". Recuerdan que decir "polista" es lo mismo que decir "indio del estado llano o plebeyo". Además, el recurrir a polistas es "propio de sociedades infantes". Si el servicio está mal, debe "apuntalarse" hasta su sustitución, y no plantearlo desde bases nuevas. Argumentan que si la prestación personal se ha reducido progresivamente desde la conquista de las islas, no es lógico que ahora se pretenda ampliar..$^{30}$ Ven la solución en que la nueva contribución ${ }^{31}$ que se proyecta introducir en el archipiélago, que habría de sustituir al tributo, se plantee como un impuesto personal basado en la riqueza, y que sean precisamente aquellos que no alcancen un mínimo impositivo determinado quienes deban cumplir con la prestación personal. Para terminar, Azcárraga y Berges no consideran aconsejable eliminar la citada exención a los cabezas de barangay. ${ }^{32}$

Como la burocracia peninsular no acaba de concretar nada en relación con la prestación personal, desde Filipinas se intenta ordenar nuevamente, aunque de forma muy básica, el servicio. ${ }^{33}$ De este modo, el 23 de diciembre de 1876, el gobernador general de Filipinas, José Malcampo, remite

29 AHN, Ultramar, 5.315, primera parte, exp. 7, doc. 5.

30 No todos estaban conformes - como es obvio - con esa reducción de la prestación. El autor de los Apuntes interesantes sobre las Islas Filipinas (Madrid, 1870), que fue Vicente Barrantes —según W. E. Retana- proponía extender el trabajo obligatorio, concediendo indios a particulares, a quienes se debería garantizar sueldo y justicia. Consideraba que éste era el único sistema para desarrollar la agricultura (págs. 213-215).

31 Se refiere a la cédula personal, pero se introduce algunos años después, en 1884 .

32 La moción del Consejo, junto con el voto particular citado, se remite al Ministerio de Ultramar con fecha 30 de marzo de 1876. AHN, Ultramar, 5.343, segunda parte, exp. 3, doc. 1 .

33 La información que ofrecemos de aquí en adelante procede de AHN, Ultramar, 5.343, segunda parte, exp. 3. Este legajo corresponde al Ministerio de Ultramar y contiene una información más densa que el 5.315, que pertenecía al Consejo de Filipinas. En aquél encontramos —además de otros papeles de menor importancia - dos grandes cuerpos documentales. En primer lugar, el expediente completo sobre la prestación personal, solicitado por el Consejo de Filipinas al Ministerio de Ultramar en abril de 1872 y remitido un año después. Está formado por un extracto y 22 documentos, fechados entre 1860 y 1868. El segundo conjunto documental es el expediente relativo a las consultas e informes emitidos sobre el anterior bloque y acerca de lo que debería hacerse sobre el tema de la prestación personal. Contiene un extracto y tres documentos: a) el dictamen del Consejo de Filipinas de 1876 comentado en el texto; b) un reglamento sobre la prestación elaborado por la Dirección General de Administración Civil de Filipinas el mismo año; y c) un informe del Consejo de Estado sobre todo lo anterior, de 1881. Además, a lo largo del extracto se reflejan — como es costumbre— las opiniones de los distintos centros del Ministerio de Ultramar y de otros organismos que estudian el expediente. 
copia del "expediente sobre formación del padrón de polistas y establecimiento de la cuenta y razón del servicio de prestación personal". Había sido elaborado por la Dirección General de Administración Civil de las islas y contenía una propuesta de decreto que, según Malcampo, vería pronto la luz pública en la Gaceta de Manila. El gobernador solicita la aprobación del decreto y anota que trata sólo los aspectos reglamentarios y de procedimiento, debiendo dictarse resolución definitiva en la península sobre las cuestiones de fondo. ${ }^{34}$

Pese a las intenciones del gobernador de Filipinas, el Ministerio de Ultramar considera innecesario estudiar lo remitido desde las islas, pues nada de aquello tendría validez si se acepta lo propuesto por el Consejo de Filipinas en marzo de ese mismo año (1876) y que aún no había sido estudiado. Esto lo escribe Julio García del Busto, jefe del negociado segundo de la Dirección de Administración y Fomento del ministerio, en nota incluida en el extracto, fechada a 30 de marzo de 1877. Con esta nota comienza otro largo proceso de información, en este caso de la propuesta hecha por el Consejo de Filipinas en 1876, que nos lleva - en una primera fase - hasta 1881. En la nota citada, García del Busto se muestra totalmente conforme con el proyecto del Consejo y rechaza el voto particular de Azcárraga y Berges. En oposición a éstos, argumenta que no es denigrante el hecho de que los españoles se conviertan en polistas, pues el trabajo no rebaja, y "sólo hay rebajados donde hay enaltecidos".

Por el contrario, la subsecretaría del mismo ministerio, dirigida por Eugenio Alonso Sanjurjo, además de aceptar el citado voto particular, propone que se oiga al respecto al gobierno de Filipinas y a la Dirección General de Hacienda (13 de abril de 1877).

El negociado segundo, ahora con Félix Díaz a su frente, considera ociosos esos informes y pide que se pronuncie el Consejo de Estado en pleno (7 de noviembre de 1877). Pese a este parecer, la Dirección de

34 El decreto reduce de 40 a 24 días la prestación, fija la redención en tres pesos y mantiene el sistema de fallas a razón de un real fuerte diario. Los servicios a realizar serían los siguientes: limpieza y custodia de tribunales; conducción del correo y partes oficiales; servicio de vadeos — cuando no estén arrendados por la administración-; y construcción y reparación de caminos vecinales, carreteras, canales, edificios del Estado y otros servicios de utilidad pública. Los trabajos se realizarían de sol a sol, con un intervalo de descanso desde las 11 a las 14 horas. En uno de los informes previos se apunta el dato de que existen 27.000 cabezas de barangay y alrededor de un millar de tribunales en todo el archipiélago, lo que supondría un millar de gobernadorcillos indígenas. Desde un estricto punto de vista económico, no parece que fuera necesaria la supresión de la exención de la prestación personal a estos personajes después de varios años de servicio continuado, aunque evidentemente el número total de exceptuados fuera notablemente superior al de los cabezas y gobernadorcillos en ejercicio. 
Administración y Fomento del ministerio solicita en noviembre del mismo año el informe de la Dirección General de Hacienda. En este momento, se produce un nuevo bloqueo administrativo que dura hasta julio de 1880. Es entonces cuando el nuevo oficial encargado del Negociado de Contribuciones e Impuestos de la Dirección General de Hacienda del ministerio localiza el expediente — que sin duda había sido retenido- - y pregunta si debe elaborarse el informe solicitado en 1877.

El proceso sigue efectivamente adelante y la Dirección de Hacienda informa en sentido negativo sobre el hecho de que sean obligados los extranjeros al cumplimiento de la prestación personal. Nuevamente pasa el expediente al negociado de Félix Díaz, quien pide que informe el Consejo de Estado. Pero antes lo hace el Negociado de Obras Públicas, desde donde - pese a estar de acuerdo con lo propuesto - se advierte de que la prestación debe desaparecer en el futuro y con ella la "semiesclavitud" del indígena. Por fin, tras un nuevo paso por el negociado segundo, se remite el expediente al Consejo de Estado. El informe de éste considera que razones de prestigio - entre otras- aconsejan no extender la prestación a españoles y extranjeros; además, dicha contribución debe terminar suprimiéndose. Por el momento, creen conveniente efectuar la proyectada reducción de 40 a 24 días, la supresión de las fallas y que se hagan los pagos de la redención en papel del Estado (30 de marzo de 1881). ${ }^{35}$

El complejo proceso que acabamos de reseñar acabó nuevamente estancado y sin ver concretada ninguna disposición. Una nota en el extracto del expediente (de 10 de abril de 1881) explica que se ha decidido dejar todo en suspenso hasta que terminen de resolverse los estudios que sobre

35 Por estos años, el gobernador general Fernando Primo de Rivera hace las siguientes observaciones. Señala que, calculado en un millón de habitantes los obligados durante 40 días a la prestación personal y siendo 75 milésimas de peso el valor de cada jornada, resultarían unos ingresos para los fondos locales de tres millones de pesos (en trabajo o en metálico). Pero si se tiene en cuenta que en casi todas las provincias el jornal suele ser mayor, podrían alcanzarse los nueve millones de pesos, cifra que, evidentemente, no se obtiene. Así pues, para el gobernador resulta imprescindible variar el sistema de recaudación. Para evitar las "filtraciones", propone que el pago de las redenciones se efectúe en papel del Estado o en sellos. Insiste en la necesidad de corregir los abusos que se producen durante el servicio: se obliga a trabajar (o a volver a pagar) a quienes ya se han redimido; se exige redimir obligatoriamente la mitad de los días; gobernadorcillos y cabezas de barangay utilizan a los polistas para su propio servicio; el dinero de las redenciones se emplea en gastos del tribunal, en regalos o fiestas; las cuentas no se llevan de manera correcta; etc., etc. (AHN, Ultramar, 5.346, segunda parte, exp. 37, doc. 1). [A diferencia de los restantes legajos citados en este trabajo, el número 5.346 aún no ha entrado — a fecha 3 de abril de 2000 - en el proceso de reclasificación de expedientes que se está desarrollando en la sección de Ultramar del AHN. El número de expediente citado en este legajo es el antiguo, escrito con lápiz azul. En los restantes, los expedientes han sido renumerados y ordenados en carpetas de cartulina]. 
la reforma del sistema rentístico de Filipinas se están planteando en el Consejo de Filipinas.

Sin embargo, quizás porque la burocracia tiende a hacer las cosas siempre al margen de la lógica, los estudios van a proseguir. El ministerio presenta a informe del Consejo de Filipinas un proyecto de decreto que nuevamente propone reducir a diez días la duración del servicio (irredimibles y sustituibles sólo hombre por hombre) y crea un impuesto provincial como compensación, por un valor de 1,5 pesos anuales. ${ }^{36}$ Pablo Ortiga y Rey (el consejero que informa) se muestra favorable a las medidas citadas, pero critica otros aspectos; entre ellos, el hecho de que se excluya de la prestación a españoles europeos y extranjeros. Lo primero sería un agravio para los españoles nacidos en Filipinas, y lo segundo - de incluirse a los chinos entre los extranjeros- además de causar graves pérdidas económicas, acarrearía disgustos y quejas entre la comunidad indígena. Ambas dificultades podrían subsanarse gracias al nuevo impuesto de cédulas personales: ${ }^{37}$ estarían exceptuados de la prestación personal todos aquellos que pagasen cédulas por un valor de tres o más pesos.

El ministro de Ultramar asume casi en su totalidad las indicaciones del Consejo y, por fin, mediante sendos reales decretos ${ }^{38}$ de 12 de junio de 1883 , se reforma la prestación personal y se crea el nuevo impuesto provincial. La exposición previa del ministro (Gaspar Núñez de Arce) es bastante ilustrativa de la situación existente y de los propósitos que se pretenden alcanzar con la reforma. El ministro apunta como causa principal de los abusos que desvirtúan la prestación al hecho de que, desde "épocas pretéritas", se permitiera la redención de los indígenas más acomodados mediante el pago de determinadas cantidades, que han sido siempre manipuladas por autoridades indígenas y jefes provinciales. Esto, unido a la falta de una reglamentación precisa y a la centralización en Manila de los fon-

36 Este impuesto se suprime en 1889, incrementándose el valor del impuesto de cédulas personales en un $50 \%$, con carácter general.

37 Por real orden de 6 de marzo de 1884, se suprimen en Filipinas los tributos de "naturales" y de "mestizos", además de otros de menor importancia, y se instaura un modelo único de impuesto general de "cédulas personales", semejante al existente en la península, que habrían de abonar, en sus distintas clases o categorías, tanto españoles como filipinos. Desde una perspectiva teórica, el cambio es de trascendental importancia, pues significa que los filipinos dejan de ser vasallos de la Corona y se convierten en auténticos ciudadanos. En la práctica, sin embargo, la innovación no tendrá consecuencias relevantes para la población.

38 Pueden consultarse, además de en las correspondientes publicaciones oficiales, en Álvarez de Mendieta, J. B.: Recopilación bi-linguae de las disposiciones referentes al servicio de la prestación personal y al impuesto provincial, Manila, 1888, págs. 7-19. 
dos sobrantes tras la creación en 1858 de la Dirección General de Administración Local, ha provocado la falta de atención a las necesidades locales y el descrédito del sistema entre la población..$^{39}$

Pero hay más circunstancias agravantes. Muchos jefes de provincia han seguido el erróneo dictado de que cumplirían mejor con su deber cuantos más fondos remitieran a Manila, exigiendo la redención obligatoria de veinte o más días de los cuarenta fijados para la prestación personal, y, lo que es peor, otros tantos han abusado constantemente del sistema de fallas, abusos de los que, como venimos anotando, también participan las autoridades indígenas. El resultado de tales despropósitos es —según el ministroque la prestación "llegue a considerarse como fuente perenne de abusos o inmoralidades y de que algunos lleguen a ser partidarios de la abolición".

Núñez de Arce rechaza tajantemente esa última posibilidad, aunque al mismo tiempo reconoce que razones sociales y políticas aconsejan reducir el servicio. Pero, como también es cierto que el presupuesto de fondos locales de 1881-82 presenta un déficit considerable, es necesario recaudar lo suficiente para superarlo, pretendiendo haber encontrado la solución en el nuevo impuesto provincial, por valor de 1,5 pesos. El objetivo de la reforma es doble y complementario: por una parte, se introduce una innovación favorable a la población indígena; por otra, se aumentan los impuestos para compensar las pérdidas debidas a la supresión de las redenciones y fallas.

Los aspectos más destacables de la reforma de la prestación personal son los siguientes: se reduce de 40 a 15 días la duración del servicio; no se admiten redenciones ni fallas, sólo la sustitución hombre por hombre; están obligados al servicio todos los varones — de 18 a 60 años-domiciliados o con residencia fija en Filipinas, sin ningún tipo de distinción ${ }^{40}$ los traba-

39 Como era muy lento el proceso de elaboración de proyectos de obras locales, gran parte de esos fondos terminaba siendo destinado a otros fines, de acuerdo con los intereses de la administración general de las islas. Otras quejas relacionadas con la utilización de la prestación personal por parte de los jefes de provincia se refieren al hecho de que, cuando aprovechan de forma eficaz dicho servicio, lo hacen mayoritariamente en las cabeceras o capitales provinciales, en las poblaciones en las que tienen su residencia, en definitiva.

40 No obstante, el listado de eximidos era bastante extenso (aunque han desaparecido algunas categorías que sí quedaban eximidas en 1863): eclesiásticos; militares en servicio activo; empleados públicos mientras desempeñan sus funciones; gobernadorcillos y ministros de justicia durante el tiempo que sirvan sus cargos y el año siguiente al que cesen en ellos; cabezas de barangay en ejercicio y sus auxiliares (los llamados primogénitos); maestros; vacunadorcillos con nombramiento oficial; fieles y estanqueros de la Hacienda pública, mientras ejerzan estos cargos; sacristanes, cantores y porteros de iglesias, catedrales, casas parroquiales y conventos; intérpretes y "testigos acompañados" de los juzgados de primera instancia y los que colaboran con gobernadorcillos y tenientes de justicia; todas las personas mayores de 60 años; los enfermos que presenten acreditación médica de su situación; cuadrilleros; todos aquellos que paguen tres o más pesos por el impuesto de cédula personal. 
jos se realizarán exclusivamente dentro del radio municipal, mientras que las obras de utilidad provincial se harán con audiencia del Consejo de Administración y autorización del gobierno de las islas.

Los citados reales decretos establecían las líneas generales de actuación en sus respectivos ámbitos, la prestación personal y el nuevo impuesto provincial. Sin embargo, en ambos casos era necesario - como de costumbre- la elaboración de reglamentos específicos que delimitaran con claridad la forma en que deberían llevarse a la práctica sus contenidos. Esta labor de reglamentación había de ser realizada en las islas, concretamente por la Dirección General de Administración Civil. Este centro redactó, efectivamente, el reglamento para la ejecución de la reforma de la prestación, que se publicó en la Gaceta de Manila el 21 de febrero de 1884. No obstante, todavía debía remitirse a la península para su aprobación definitiva. Así se hizo, cumpliéndose en este caso los trámites con relativa celeridad. El 30 de septiembre del mismo año, el Ministerio de Ultramar pasó dicho reglamento al Consejo de Filipinas para su informe, que resulta extenso y detallado. ${ }^{41}$

Comienza rectificando el sistema de empadronamiento propuesto, al tiempo que advierte de que debe desaparecer la diferenciación que se hace en los padrones entre españoles, naturales, mestizos, extranjeros y chinos. Por otro lado, el reglamento no instaura ningún sistema para evitar que los polistas trabajen más o menos de lo ordenado; deberán fijarse claramente, por tanto, los derechos y obligaciones de los trabajadores y limitar el número de días continuados de servicio. Propone el Consejo que se contabilicen como jornadas de trabajo los desplazamientos largos y se consideren como servicios de doble valor los realizados durante la noche, como la conducción del correo o pliegos. Advierten de que en el reglamento se interpreta erróneamente lo señalado por el real decreto sobre imposición de multas a aquellos que no cumpliesen con la prestación. El citado decreto establece 0,5 pesos de multa por cada día que se dejare de acudir al servicio, pero su pago no exime del trabajo, pues de otra forma se restablecería el sistema de fallas que tan perjudicial había sido.

Aunque recomiendan expresamente que se controle muy de cerca que las autoridades indígenas no utilicen la prestación personal de forma despótica o arbitraria, consideran que el reglamento trata con excesiva dureza a los gobernadorcillos y cabezas de barangay, en cuanto a las faltas cometi-

41 AHN, Ultramar, 5.307, segunda parte, exp. 27, doc. 17. Fue publicado por Álvarez de Mendieta: Recopilación..., págs. 19-61. 
das en el servicio, y que es igualmente demasiado estricto con los polistas que acuden con retraso al trabajo o que se muestran "insolentes". Por otro lado, los cabezas de barangay —institución que preocupa especialmente al Consejo- deben verse liberados de tareas, y entre otras no debería obligárseles a asistir constantemente a las obras públicas.

El Consejo concluye su extenso dictamen señalando que el reglamento no puede tener carácter definitivo, sino que debe regir provisionalmente, con las modificaciones propuestas, hasta su reforma.

El ministerio acepta el dictamen del Consejo y lo remite a Filipinas con fecha 3 de febrero de 1885 - fijando al mismo tiempo el plazo de "tres meses a contar del cúmplase de esta real orden, para la formación y remisión del reglamento reformado".

En la Dirección General de Administración Civil de las islas no debió de recibirse con mucho agrado el crítico informe del Consejo. El caso es que el plazo de tres meses establecido por el ministerio se convierte en dos años. Hasta el 13 de enero de 1887 no aprueba el gobernador general, Emilio Terrero, los nuevos reglamentos de la prestación personal y del impuesto provincial. ${ }^{42}$ El director general de administración civil de Filipinas, Benigno Quiroga — de talante liberal—, al elevar el reglamento al gobierno general para su aprobación provisional, hace unas interesantes observaciones que giran en torno a una idea principal que expone con total claridad: las dificultades y abusos que conlleva el servicio de la prestación personal tienen una solución radical que sería la más conveniente a los intereses públicos, y esa solución no es otra que la supresión. La argumentación es clara y contundente:

"Es él [el servicio de la prestación], cualquiera que sea el número de días que abrace, vejatorio por su índole; injusto, si admite excepciones por razonables que sean, ocasionado a abusos de todo género, gran elemento de inmoralidad y después de todo absolutamente inútil e ineficaz para el servicio de las obras públicas, para cuya aplicación preferente se le invoca.

No son razones de índole técnica las que pueden apoyar este aserto; no son los inconvenientes de la reorganización diaria de brigadas, ni la imposibilidad de utilizar aptitudes, ni la necesidad de llevar a las obras el espíritu de la más severa disciplina, indispensable donde quiera que haya agrupaciones de individuos que deben ser obedientes a un plan común, ni la desventaja que tiene el trabajo no retribuido respecto del que se obtiene por un salario, razones que se necesiten aducir en contra de tan odiosa imposición: basta ver que después de tantos años de utilizarse en estas islas

42 Ibídem, págs. 57-108. 
una prestación de más de 40.000 .000 de peonadas anuales, no hay edificios para los servicios públicos, no hay puentes, no hay caminos; solo huellas de que allí donde una administración honrada aplicó este recurso lo hizo sin la menor inteligencia, y allí donde lamentables negligencias lo consintieron, solo han quedado tristes recuerdos y deplorabilísimos ejemplos."

Pese a mostrar Quiroga una opinión personal de tal alcance, razones políticas le obligan a plantear la reforma proyectada y a presentar el nuevo reglamento. Éste sigue fielmente las líneas propuestas por el Consejo de Filipinas y resulta bastante conciso en su ordenamiento. Se divide en dos títulos: prescripciones generales y reglas de procedimiento. El título primero lo componen tres capítulos: contribuyentes y exceptuados, definición de los servicios y organización administrativa del servicio. El título segundo reúne cinco capítulos: formación de padrones, distribución del trabajo personal, citaciones y concurrencias al trabajo, inspección y vigilancia y correcciones y multas.

No vamos a detenernos a analizar el articulado del reglamento, pero sí podemos destacar algunos aspectos particulares. En principio, la reglamentación trata de evitar cualquier exceso en la gestión de la prestación personal; de este modo, el artículo octavo define una peonada, o día de trabajo por persona, como la dedicación laboral durante ocho horas consecutivas, con un descanso intermedio de dos horas. Además, se contabiliza dentro de esas ocho horas "el tiempo necesario para la ida y vuelta al trabajo a razón de media hora por cada kilómetro de distancia, para los polistas avecindados en visitas, rancherías, sementeras o despoblados [...]". Las horas de trabajo nocturno se habrían de cuantificar como dobles, al igual que las jornadas empleadas por polistas con oficio si ejercieren éste en el servicio.

Por supuesto, la parte ejecutiva de los trabajos quedaba a cargo de los gobernadorcillos, pero asistidos por una junta local, que él mismo presidiría, formada por el gobernadorcillo de mestizos — donde lo hubieracomo vicepresidente, el teniente primero, los jueces de policía, de ganados y de sementeras y "dos vecinos pudientes designados por el Jefe de la provincia a propuesta del R. o D. Cura párroco, siempre que éste tenga a bien hacerlo y en otro caso a elección de aquel". El directorcillo o escribiente primero desempeñaría el cargo de secretario sin voz ni voto.

La nueva reglamentación de la prestación personal, después de tan extenso y penoso proceso de elaboración, disfrutó de una corta vida. Tras la reforma de la administración municipal insular en mayo de 1893, los 
pueblos con mil o más cédulas ${ }^{43}$ pasan a disponer de la prestación personal como recurso propio, perdiendo así el carácter provincial que hasta entonces tenía. ${ }^{44}$ Por esta misma razón, un superior decreto de 7 de julio de 1893 ordenaba que, desde el año siguiente, los capitanes (esto es, los gobernadorcillos) de Luzón y Visayas, cesaran de ejercer las tareas que sobre el control de la prestación personal les estaban hasta entonces encomendadas. Se encargarían de ello las nuevas corporaciones, que debían proponer al gobierno de las islas las reformas conducentes a la consecución de una auténtica administración municipal de la prestación.

La Dirección General de Administración Civil, tratando de orientar a los jefes de provincia afectados por la variación, les dirigió una circular, firmada por Ángel Avilés, con fecha 31 de julio de ese mismo año de $1893 .{ }^{45}$ El director insiste en los tópicos que ya veíamos en decretos y órdenes anteriores: "en otro tiempo", asegura, la prestación fue muy importante, pero "hoy [...] es fuente de abusos e inmoralidades". Es decir, la reforma de 1883 - y el reglamento de 1887- no parecen haber logrado modificar en sentido positivo la administración de la prestación personal. Los principales inconvenientes, según Avilés, son:

"l. ${ }^{\circ}$ La distancia y la disposición del caserío en los barrios rurales, que dificulta las citaciones de los polistas y a éstos les imposibilita de asistir a los trabajos comunales cuando las obras están distantes, por la necesidad de volver a sus viviendas a medio día para comer y regresar de nuevo al sitio donde las obras se ejecutan.

2. ${ }^{\circ}$ La falta en los Tribunales de los pueblos de personal suficiente, para con el celo debido verificar las citaciones.

3. ${ }^{\circ}$ La falta de medios coercitivos para obligar al indígena al cumplimiento de este servicio."

Todo lo anterior — habría que advertir- en el mejor de los casos. Para vencer esas circunstancias adversas, recomienda:

"l. ${ }^{\circ}$ La distribución de los trabajos en forma tal que solo concurran a una obra los individuos de las cabeceras más inmediatas, haciendo que trabajen los quince días consecutivos o por semanas alternadas.

2. ${ }^{\circ}$ Circunscribir por punto general el servicio de la prestación a los trabajos de apertura, arreglo y reparación de calzadas, y al acarreo de tierras para los terraplenes

43 Esto es, aquellos en los que hubiera mil o más contribuyentes que abonaran el impuesto de la cédula personal.

44 Sobre la reforma municipal de 1893, se puede consultar Sánchez Gómez: "Vísperas del 98...".

45 Se publicó en la Gaceta de Manila, el 2 de agosto de 1893. La reproduce Artigas: El Municipio filipino... , I, págs. 53-57. 
de los puentes, construcción de cunetas, etc., servicio de vadeos, conducción de correspondencia y otros análogos, dado que inútil e ineficaz resulta hoy este concurso para el servicio de obras públicas, a cuya aplicación preferente se viene dedicando.

3. ${ }^{\circ}$ Vigorizar la acción de las Juntas y nuevos Tribunales en lo relativo a la imposición de multas [...]."

Estas recomendaciones se oponen en buena parte a las medidas que venían planteándose desde tiempo atrás, tanto en lo referente a las obras a realizar, como - y principalmente — al reparto de los días de trabajo, pues la reglamentación vigente aconsejaba que no fueran más de dos las jornadas consecutivas trabajadas por cada polista. Precisamente, muchas de las quejas de éstos tenían como base el hecho de que se les obligara a trabajar de forma continuada, lo que impedía que pudieran mantener sus sistemas de subsistencia durante las épocas de la prestación.

Para concluir, podemos señalar que aún hubo un intento más de reformar alguna de las cuestiones relativas a la prestación personal. En efecto, esto ocurría en el suspendido real decreto de 12 de setiembre de 1897 que intentaba reformar la legislación vigente en Filipinas. En otro lugar ${ }^{46}$ hemos comentado cuál era el objetivo que perseguía el gobierno de la metrópoli con este decreto, de ahí que no insistamos en ello. Es el artículo séptimo el que afecta a la prestación, y dice así: "El número 15 del artículo 24 del real decreto de 19 de mayo de 1893, se redactará en los siguientes términos: 'El servicio de prestación personal que no sea redimido"”.

El mencionado real decreto es el que reformaba la administración local de las islas y el citado número 15 se refería a "los quince días de la prestación personal" como uno de los nuevos recursos municipales. Al pretender sustituir la frase original por la citada, se entiende que existe la posibilidad de redimir la prestación personal; con la reforma, por tanto, sólo pasaría al haber de los pueblos el trabajo de la prestación, no el importe de las redenciones. Sin embargo, como ya dejamos señalado, el real decreto de 12 de julio de 1883 decía claramente en su artículo segundo que no podría redimirse en metálico ninguna de las jornadas, siendo únicamente válida la sustitución hombre por hombre. Ante esta situación, sólo podemos plantear dos explicaciones: o el gobierno peninsular de 1897 desconocía las líneas básicas de la legislación sobre prestación personal o, si lo anterior no era cierto, lo que sucedía era que, pese a lo legislado, se man-

46 Sánchez Gómez: "Vísperas del 98 ....". 
tenía el cobro de las redenciones; por tanto, la reforma pretendía evitar que esos fondos pasaran a ser utilizados por los municipios, para que de este modo no pudieran servirse de ellos los rebeldes levantados en armas contra la dominación española. Por la información de que disponemos, parece evidente que, de un modo u otro, la administración general de las islas había permitido, contraviniendo la legalidad vigente, el mantenimiento de las redenciones en metálico, ${ }^{47}$ dado el valor de este recurso para las arcas locales y provinciales.

Como conclusión general sobre el tema del tributo ${ }^{48}$ y la prestación personal, podemos señalar, sin temor a equivocarnos, que las reformas liberales del siglo XIX en materia tributaria van a incidir negativamente tanto en el llamado "común del pueblo" como en las principalías y gobiernos indígenas. La idea tan manida después de 1869 de que era necesario reformar un sistema tributario claramente injusto, en el que pagaban igual ricos y pobres, no sólo no se lleva a la práctica, sino que incluso se introducen variaciones que empeoran la situación. En principio, el sistema de cédulas personales instaurado en 1884 pretende hacer contribuir de acuerdo con la riqueza personal, pero lo único que consigue es que el timaua, cailian o "indio del común" pague más y que los mejor situados económicamente contribuyan, es cierto, con cantidades algo mayores, pero esta circunstancia les sirve para redimirse completamente de la prestación personal. ${ }^{49}$ Por otra parte, la introducción del impuesto provincial viene a significar, desde una estricta perspectiva crematística, la restauración del antiguo tributo, con la carga negativa consiguiente para los más pobres. La supresión de ese impuesto en 1889 no alivia la situación, ya que como compensación se incrementa el valor de la cédula personal. Además, continúa vigente en la práctica, pese a lo legalmente establecido, el sistema de redenciones de la

47 No obstante, cuando en alguna ocasión una determinada autoridad provincial solicita de forma expresa la recaudación en metálico de la redención de la prestación personal, la autoridad superior de las islas se lo niega. Eso es lo ocurrido al gobernador político-militar de Cebú en 1894. Entonces, en el nuevo contexto creado tras la reforma municipal de 1893, el gobernador intentará, sin éxito, que la Dirección General de Administración Civil apruebe el cobro de las prohibidas redenciones de la prestación personal, para que estos fondos sirvieran al desarrollo económico de las nuevas corporaciones, ya que carecían prácticamente de cualquier otro tipo de ingresos, encontrándose los recién creados municipios en una situación ciertamente lamentable. Ver Sánchez Gómez: "Vísperas del 98...", págs. 36-38.

48 Aunque nuestro estudio se ha centrado en el servicio de la prestación personal, es obvio que sólo se puede valorar su importancia en el entramado hacendístico filipino si se pone en relación con el complejo y significativo mundo de la tributación personal. Un excelente estudio al respecto, enmarcado entre los años de 1762 y 1868, es el que nos ofrece Fradera: Filipinas..., págs. 133-190.

49 La única mejora efectiva para el "común de los naturales" es la reducción del número de días de la prestación personal. 
prestación: los miembros del "común de los naturales" que desean verse libres del trabajo pueden seguir recurriendo al pago de tres pesos, con el consiguiente quebranto económico.

En último término, y pese a todos los debates y a las múltiples opiniones en contra, la prestación personal no desaparece. Y lo peor de todo es que no existe una legislación específica sobre la prestación personal, de aplicación general a todo el archipiélago, hasta 1887, cuando se aprueba el reglamento para el desarrollo del decreto publicado en 1883. Hasta entonces, y aún seguramente después, podríamos asegurar que en cada provincia se continúa con la inercia de modelos generados en épocas pretéritas. Por otra parte, es evidente que con la extensión de este servicio al conjunto de la población, los gobiernos liberales de la península quieren hacer creer que están allanando las "diferencias de raza", que se está igualando, en definitiva, a los españoles — criollos o peninsulares - con sus "hermanos filipinos". Sin embargo, como hemos comprobado, la posesión y el pago de una determinada cédula personal, a partir de 1884, libra de la prestación personal a todos aquellos que siempre habían estado al margen de la condición de polista. De este modo, la anacrónica prestación personal, el trabajo obligatorio y gratuito del indígena filipino, continuará siendo hasta 1898, como lo había sido desde hacía siglos, el principal mecanismo disponible para el desarrollo de las infraestructuras de comunicación y de servicios en las islas.

Por otra parte, las principalías indígenas locales y provinciales, a quienes aún interesa participar en los gobiernos de los pueblos, se verán igualmente perjudicadas por las reformas. Aquí también los resultados son frontalmente opuestos a los planteados por numerosos políticos y administradores de las islas y la península. Desde mediados del siglo XIX, y sobre todo después de 1868, una de las ideas fundamentales que se utilizan como bandera de la regeneración de los pueblos indígenas es precisamente la que propugna la devolución del prestigio y privilegios perdidos a los gobernadorcillos y cabezas de barangay. Muchos creían que éste era el único camino para mejorar la administración local, conservar fieles a España a los filipinos y fomentar el desarrollo económico de las poblaciones. Sin embargo, todo esto desaparece en los decretos ${ }^{50}$ y reglamentos liberales. Los privilegios históricos de las principalías - exención en el pago del tributo y en la prestación personal— quedan limitados al periodo

50 Recordemos, por otra parte, que la tradición de legislar mediante decreto, sin el más mínimo consenso parlamentario, va a caracterizar a la política española sobre Filipinas durante toda su historia. 
de disfrute de los cargos municipales y al año inmediatamente posterior al abandono del puesto. Se elimina la posibilidad de transformar en vitalicias esas prebendas por haber servido los cargos durante un tiempo prolongado. Evidentemente, esto sólo podía incidir en que tales principales y autoridades locales trataran de resarcirse de sus gastos y perjuicios presionando sobre sus cailianes.

Finalmente, tampoco podemos dejar de señalar que los pueblos de indios no van a gozar de ventajas importantes por las reformas. La centralización presupuestaria existente hasta los años 80 se va a intentar trasformar en semicentralización provincial. Sólo el nuevo esquema municipal de 1893 posibilita a los tribunales municipales el acceso a recursos económicos propios, entre ellos la prestación personal. ${ }^{51}$ Pese a todo, y al margen de tratarse de unos recursos claramente insuficientes, ya era demasiado tarde. En realidad, hacía tiempo que "era tarde", ya que ni siquiera después de 1868 los gobiernos españoles de turno fueron capaces de asumir ninguna de las comedidas reivindicaciones planteadas desde las islas. No se acepta la representación en Cortes de los filipinos ni se abordan verdaderas reformas políticas. Las cicateras reformas administrativas quedaban muy lejos de lo que habría esperado recibir de la metrópoli una buena parte de la sociedad filipina "ilustrada" de la época.

51 Sólo el trabajo, ya que legalmente no existe la redención, aunque de hecho ésta se mantiene, como hemos visto. 